\title{
Role of Medical Representatives in Influencing Medicine Prescription Behaviour of Doctors
}

\author{
Kiran Bala ${ }^{1}$ and Kavita Sharma ${ }^{2}$ \\ 'Assistant Professor, Department of Commerce, Delhi School of Economics, University Enclave, Delhi - 110007, \\ India; kirandu02@gmail.com \\ 2Professor, Department of Commerce, Delhi School of Economics, University Enclave, Delhi - 110007, India; \\ ksharma.dse @gmail.com
}

\begin{abstract}
Medicine Prescription Behaviour (MPB) is a doctor's decision for a specific drug/medicine of a pharmaceutical company. Doctors consider several factors in their evaluation process while selecting a particular drug. The transfer of information to doctors, especially through detailing by Medical Representatives (MRs), is a crucial element of pharmaceutical marketing. New drugs are introduced in the market very frequently because of rapid change in preferences and prescription patterns of doctors. Therefore, understanding shift in doctors' desires regarding selection of a particular drug give opportunities to proactive pharmaceutical companies to increase their market share by timely anticipating doctors' preferences. This paper seeks to identify the influence of level of knowledge, kind of information, communication skills and frequent visit of MRs on three aspects of MPB; early prescription of new drugs, cost of drugs and habitual aspect. Testable hypotheses were developed with respect to MPB and a survey questionnaire was designed to capture data from 150 doctors practicing in Delhi. The hypotheses were tested using Multiple Regression and Analysis of Variance (ANOVA). The study concluded that the knowledge, kind of information, communication skills and professionalism factor of MRs influence doctors towards early prescription of new drugs and their habitual behaviour towards prescription of drugs. The study concluded that knowledge and the kind of information given by MRs are significant predictors of cost aspect of MPB of doctors.
\end{abstract}

Keywords: Drugs, Medical Representatives, Medicine Prescription Behaviour, Pharmaceutical Marketing JEL classification: M31, M37, C91

\section{Introduction}

Pharmaceutical industry in India is the world's third largest in terms of volume and stands $14^{\text {th }}$ in terms of value. There are approximately 30,000 pharmaceutical companies in India, competing for a share in the 20 billion dollar annual market. Pharmaceutical companies spend a huge amount per year in promoting their drugs to doctors who prescribe the medicines to their patients. According to past researches, pharmaceutical companies in U.K., invest approximately 26 percent of their sales in promotion of their drugs to doctors. This amount is greater than what they spend on research and development.

Medicine prescription, which involves doctor's decision about a specific pharmaceutical company's drugs through their evaluation process is based on considerations about prescription of new drug, cost and safety of the drug and its brand name. Pharmaceutical marketing attempts to educate doctors about the promoted drugs for influencing their MPB. Pharmaceutical companies appoint Medical Representatives (MRs) and assign them defined territories to meet doctors, chemists and stockists. MRs, who form the backbone of pharmaceutical marketing, meet doctors to influence their prescription pattern in favour of their brands ${ }^{49}$. MRs are considered as important sources of information for doctors in making their prescription decisions. Wazana ${ }^{\underline{54}} \&$ Alkhateeb et al. $\underline{\underline{3}}$ found that there is clearly a substantial, though variable, effect from one-to-one drug information delivery.

*Author for correspondence 
MPB is a study that involves understanding a process that leads to selection and taking decision towards the prescription of a drug. Its three aspects are, early prescription of new drugs, cost of the drug and habitual aspect of MPB of doctors. It has been investigated largely in aggregative or overall terms, however, there is a need to know how various MR factors operate in influencing the specific aspects of MPB so that MR tools and techniques ${ }^{\mathrm{a}}$ can be used more strategically by the pharmaceutical marketers.

The paper is divided in eight sections. Objectives of the study are outlined in Section 2. Section 3 discusses three aspects of MPB of doctors i.e., early prescription of new drugs, cost of the drug and habitual aspect of MPB. Further, factors defining role of MRs in influencing doctor's MPB are discussed to develop hypothesised relationships for the purpose of their empirical testing in Section 4 and Section 5 respectively. Section 6 explains research methodology used for the present study. Section 7 gives analysis of results. The study concludes with its implications in Section 8.

\section{Objectives of the Study}

The objectives of the study are two-fold;

- To study the factors related to MRs affecting the three aspects of MPB - 1. Early prescription of new drugs, 2. Habitual aspect and 3. Cost of the drug.

- To draw strategic marketing implications for pharmaceutical companies.

Pharmaceutical companies use different marketing strategies for detailing and promoting their drug because drug promotion has a very important role in stimulating prescription behaviour of doctors. To reveal the significant factors that dominate the doctor's prescription behaviour in India, this research systematically summarizes various factors related to MRs.

The proposed study explores the pattern of prescription behaviour and major factors related to MRs influencing doctor's drug prescription behaviour in India with focus on specialists and general practitioners.

\section{Aspects of MPB}

\subsection{Early Prescription of New Drugs}

Pharmaceutical categories are characterised by a large number of new product launches. For instance, around 41 completely new drug molecules were launched every year on an average during 1994 to 2003 (IMS Health, 2009)
Narayanan et al. $\stackrel{42}{ }$ showed that the role of marketing communication for new products changes over time. They specified a model where doctors learn about the quality of new drugs through marketing communication including detailing and doctor's meetings as well as their accumulated usage experiences. They found that detailing by MRs has a indirect (learning) effect in the initial stages of the product's life cycle and a direct (persuasive) effect later on. On the other hand, Cosceilli and Shum ${ }^{14}$ explained the slow diffusion of a new drug in an existing product category through slow learning (only from patient feedback) about its quality by risk-averse doctors. Layton et al. $\frac{36}{6}$ also indicate that doctors consider MRs as a major source of information about the launch of new drugs.

\subsection{Habitual Aspect}

Prescription loyalty or continuity in prescribing the same company's drugs is also a very important phenomenon in habitual prescription behaviour ${ }^{31}$. This could be derived from the trust that the doctor develops in the pharmaceuticals company. Bednarik ${ }^{\underline{7}}$ explained how trust in pharmaceuticals is developed and influenced. He suggested that trust about a particular drug develops in the mind of the doctors because of communication skills of MRs and their professional nature.

Furthermore, trust in pharmaceuticals seems to evolve from repetitive product usage accompanied by positive experiences. Positive experience gained during the treatment phase is decisive for product usage in repeated and habitual prescriptions.

\subsection{Cost of the Drug}

Doctors consider cost as an important factor in influencing their $\mathrm{MPB}^{4,5}$. Prosser \& Walley ${ }^{45}$, in their qualitative study conducted in UK, found that doctors give valuable attention to cost in their medicine prescription decisions. Another study, in their empirical survey conducted in Israel, also concluded that doctors get knowledge about the cost of the drug through marketing tools of pharmaceutical companies $\underline{25}$.

\section{Factors Related to MRs and the Aspects of MPB}

MRs personality refers to doctor's assessment that a particular medical representative is friendly, nice and pleasant to be around. Psychological research generally 
finds a positive relationship between a person's likability and the extent to which the person is trusted by others. Doney \& Cannon ${ }^{15}$ found that salesperson likability positively influences buyer trust. When the likable MR was found to be trustworthy, doctors tend to continuously prescribe the drugs of the particular medical representative's firm. Prounis ${ }^{47}$ has excellently expressed that the relationship between MRs and doctors is very important and crucial.

Janakiraman et al. $\frac{31}{}$ investigated doctor's habit persistence in prescription choice behaviour and found significant levels of persistence in drug choice. They described doctor's current drug choice as structurally dependent on the previously prescribed drugs. They argued that doctors do not frequently change their preferences; they tend to be either persistent or non-persistent. With respect to doctors' response to the promotion of prescribed drugs non-persistent doctors were found to be responsive to detailing and symposium meetings, whereas persistent doctors seem to be responsive only to symposium meetings, In general, outside-office events, such as golf or lunch, were found to have no effect on doctor's choice. They further found that detailing and symposiums can have long-lasting effects. Experienced doctors and those who work in smaller practices are more likely to be persistent and doctors who are more willing to receive sales force representatives have a lower likelihood of being persistent.

\subsection{Level of Knowledge of MRs}

Although MR performance is measured in terms of sales, however, the job does not only entail the sale of medicines. They need to have strong product knowledge and should be able to communicate to doctors about how a certain drug is beneficial for the patients. This includes introducing the drug to doctors, educating the doctors on the possible medical issues that the drug addresses and the correct dosages as well as its advantages over that of the competitors. Doctors also value those MRs who have extensive knowledge of their drug and the correlating disease state and of doctor's needs and time constraints.

Scott' $\mathrm{s}^{50}$ survey covered almost 2,000 doctors about information that would convince them to prescribe more of a certain product. The results showed that 'objective information about the product is the most convincing item a sales representative can offer'. The Accenture ${ }^{2}$ study shows primary care doctors regard MRs as being more influential upon their early prescribing decisions of new drugs than even their own peers. According to the study, peer reviewed clinical journals (80 percent) and industry association meetings (34 percent) were rated higher than recommendations from sales representatives (30 percent). While colleagues (27 percent) and the internet (16 percent) lagged behind in comparison. Although the study was limited in size (based on a sample of 100 doctors), the respondents did indicate that 'approximately one-third of sales visits of MRs are helpful'.

Doctors want more current, comparative and clinical information based upon objective sources of information. Doctors wished to meet MRs because of the value of samples and due to their interest in new products and drug-specific information. In this study, doctors responded strongly to three components of an effective sales call: wellutilized resources, solid message content and clear message delivery. The components of the sales message that were essential to doctors were dosing, side effects, efficacy and competitive data. Health Strategies Group (2003) ${ }^{27}$, in its study, tracked doctors who received sales calls that contained one, two, or all of these key components. Only five percent of all calls contained all four key tactics, and these calls were the only ones that led to a change in MPB. The study also explored the connection between pharmaceutical representative interaction and formulary requests, and it showed that the two are positively correlated. A group of doctors who had requested formulary additions was compared to a group who had not assessed according to doctors' self-reported associations with drug company representatives. The first group was more likely to have spoken for or performed research for drug companies. Moreover, doctors were more likely to have requested formulary additions made by the companies whose pharmaceutical representatives they had met $^{27}$.

A retrospective literature review authored by Wazana ${ }^{54}$ attempted to identify the meaning of doctor-pharmaceutical representative interactions. In this article, a total of 29 studies were examined, that focused on family medicine, internal medicine and resident doctors. The results were reported with regard to the effects of interactions with pharmaceutical representatives, gifts, samples, industry-paid meals, funding for travel to attend educational symposia, continuing medical education sponsorship and doctor honorarium. The author stated that interactions with MRs were found to impact the prescribing practice of residents and doctors in terms 
of ignoring cost, non-rational prescribing, awareness, change their habit, early prescribing of new drugs, and decreased prescribing of generic drugs. In a survey study by Wazana ${ }^{54}$, that included 29 studies published during 1982-1998 with a total sample population of 8,122 doctors and residents, the author suggested that interactions guidelines, practical training, academic detailing and industry-independent drug information mailings may mitigate the influences that representatives have on doctor prescribing. An interesting finding of the article is that most doctors and residents denied that gifts influenced their behaviour. There were mixed reactions over interactions with the pharmaceutical industry and the extent of the influence upon prescribing behaviour. The three factors identified in this review that applied the greatest influence on doctors behaviour were detailing by MRs and samples and conference travel funding given by the company.

Thus, on the basis of above discussion, we hypothesise that:

MRs' knowledge has positive impact on early prescription of new drugs $\left(\mathrm{H}_{1.1}\right)$, on building habitual aspect in MPB of doctors $\left(\mathrm{H}_{1.2}\right)$ and on consideration of cost of the drug as an aspect of MPB of doctors $\left(\mathrm{H}_{1.3}\right)$.

\subsection{Kind of Information given by MRs}

MRs have been the main channel for transmitting marketing information through detailing to doctors for the past 50 years that affect habitual aspect of MPB of doctors. The main sources of information for doctors include peer-reviewed medical journals, medical textbooks, proceedings of conferences and $\mathrm{MRs}^{53}$.

Lurie et al. $\stackrel{38}{ }$ showed that drug promotion through interaction between MRs and doctors results in a significant increases in early prescription of new drugs and affects the habitual aspect of MPB of doctors. Similarly, it was found that doctors' early prescription of new drugs was influenced by pharmaceutical companies' strategies to change their prescribing patterns. Abdelaziz et al. ${ }^{\underline{1}}$ findings also indicate that MRs provide reliable and efficient information. On the other hand, Ziegler et al. $\frac{56}{}$ argue that MRs provide biased information as they only mention the advantages of the drug and doctors also consider cost of the drug in their MPB.

According to Henry ${ }^{28}$, in US the number of MRs increased from about 30,000 to over 80,000 from 1994 to 2002. MRs have increased as a percentage of office-based doctors from 10 percent in 1994 to over 20 percent in 2002. A comprehensive overview of doctor perspectives on prescription drugs was developed by this study. This study focused on interactions with representatives, drug advertising and doctor interactions with patients. A total of 2,608 actively practicing doctors responded to a mail survey. The sample was racially and ethnically weighted to be representative of the total doctor population. The survey revealed that almost three quarters of doctors rate information from pharmaceutical representatives as either very or somewhat useful. An even higher number, 80 percent, believe that the information they receive from representatives is very or somewhat accurate. In this survey, 60 percent of doctors were aware that pharmaceutical companies possess data on individual prescribing, but less than a third considered this practice to be unacceptable.

Mckinney ${ }^{40}$ concluded that 47 percent of the doctors agreed that MRs provide all information to describe a drug, while 80 percent thought that they overemphasized the effectiveness of a drug. Doctors agreed that MRs provided useful and accurate information about newly and already established drugs, but only few doctors agreed that they performed an important teaching function $\frac{32}{}$.

Norris et al's. ${ }^{43}$ study showed that 68 percent of doctors in Turkey thought the information provided by MRs was unreliable, and they don't practice early prescription of new drugs. Zeigler et al. $\frac{56}{}$ quantified the inaccuracies in MRs presentations by analysing 106 statements made during 13 presentations. 11 percent of the statements were inaccurate in favour of the promoted drug. Of the 15 statements about competitors' drugs, none were favourable. 49 percent of accurate statements about the promoted drugs were favourable, 31 percent were neutral and 15 percent were unfavourable. A questionnaire was distributed to a sample of 27 residents who had attended the presentations. Only 26 percent of them recalled having heard a representative make an inaccurate claim.

Thus, we hypothesise that:

Objective Information given by MRs has positive impact on early prescription of new drugs as an aspect of MPB of doctors $\left(\mathrm{H}_{2.1}\right)$, on building habitual aspect of MPB of doctors $\left(\mathrm{H}_{2.2}\right)$, and on consideration of cost of the drug aspect of MPB of doctors $\left(\mathrm{H}_{2.3}\right)$.

\subsection{Communication Skills of MRs}

The Indian pharmaceutical industry's biggest challenge lies in reinventing communication. Pharmaceutical com- 
panies have to primarily depend upon personal selling to promote (communicate) their medicines in the market as the target audience is doctors who are not end users.

Communication is the most important aspect of MRs and the main objective is to make a long-lasting impression on doctors. In today's competitive environment, many national and multinational pharmaceutical companies have gained remarkably through their exceptional marketing communication strategies for relationship building and sales promotion. As discussed above in pharmaceutical marketing, relationship with doctors is very important and they cannot make a good relationship until they understand their customer well.

The medium of communication, i.e. the MR is the face of the pharmaceutical company and only he can create an impact on the prescriber of the medicine. It is very important to see that the MR delivers the message appropriately. Pharmaceutical companies direct all their efforts to promote their medicine to doctors and train the field sales force to take on the task of promoting medicines to highly skilled and knowledgeable doctors. Hence, pharmaceutical selling is distinct from other kinds of selling. Pharmaceutical companies need to understand the importance of simple, creative, and effective communication in pharmaceutical selling. The objective of pharmaceutical marketing is to make profits through satisfying customer needs and wants.

The impact of promotions on doctor's choices of prescriptions has been well investigated in the literature (Berndt et al.. $;$; Gonul et al..22) and the conclusion is the strong positive influence of free samples and communication skills on doctor's prescribing habits and their early prescription of new drugs. Continuous training for MRs is designed to ensure the quality of their presentations during promotional visits to influence the cost of the drug and habitual aspects of MPB".

Thus, we hypothesise that:

Communication skills of MRs has positive impact on early prescription of new drugs as an aspect of MPB of doctors $\left(\mathrm{H}_{3.1}\right)$, on building habitual aspect of MPB of doctors $\left(\mathrm{H}_{3.2}\right)$ and on consideration of the cost of the drug as an aspect of MPB of doctors $\left(\mathrm{H}_{3.1}\right)$.

\subsection{Frequency of Visits of MRs}

A regular visit by a smart, dedicated and well groomed MR having effective soft skills is the best tool of promotion for a pharmaceutical company. Regular follow-up means doing something special or unique by the pharmaceutical companies so as to make the doctor recall the product or conducting an activity that will continuously hammer the product in the doctor's mind. Regular follow-up mainly includes frequent visits of MRs, sending a reminder card to doctors to request them to prescribe their product.

Most doctors change their habit of prescribing particular drug from one company to another by attendance of MRs, regardless of whether it is a branded drug or a generic drug ${ }^{51}$. An Indian study based on a survey conducted in the state of Haryana, showed that doctors consider regular visits by good personality $\mathrm{MR}$ as the best tool of promoting a medicine $e^{6}$.

Rajan ${ }^{48}$ found that the regular visit by a MR helps their brand to get into the mind space of a busy doctor and results in early prescription of new drugs. Every product, old or new, requires extensive marketing. Any doctor will vouch that if a particular company's MR fails to show up for over a month, he suspects the availability of the products of that manufacturer.

Thus, we hypothesise that:

Frequent visits of MRs have positive impact on early prescription of new drugs as an aspect of MPB of doctors $\left(\mathrm{H}_{4.1}\right)$, on building habitual aspect in MPB of doctors $\left(\mathrm{H}_{4.2}\right)$ and on consideration of the cost of the drug aspect of MPB of doctors $\left(\mathrm{H}_{4.3}\right)$.

\subsection{Professionalism Factor of MRs}

When doctors perceive a particular MR as having high professional values, it enhances the trustworthiness of the MR that translates into the continuous early prescription of the company's new drugs ${ }^{15}$. Unless a doctor's perceptions are positive about a particular MR in terms of professional values, they may not trust that MR and consequentially not early prescribe his company's drugs and change their habit of prescribing old drugs ${ }^{55}$.

Mizik \& Jacobson's $\mathrm{s}^{41}$ study is the most comprehensive assessment of MRs influence on doctor prescriptions. They used econometric analysis to quantify the persistence in doctors prescribing accounting for own-growth and competitive stealing effects. The study also assessed the diminishing effects over time and controls for spurious correlations of doctor-related factors. Caudill et al..$^{11}$ shows that MRs' influence upon doctor prescribing is directly correlated with the level of credibility that they have with a doctor. Almost five hundred primary care doctors in a study assessed the costs of prescribing and 
the credibility of MRs. A positive correlation was found between representative activity and credibility and the costs of prescribing, especially for the doctors practicing in non-academic settings ${ }^{11}$.

Thus, we hypothesise that:

Professionalism factor of MRs has positive impact on early prescription of new drugs as an aspect of MPB of doctors $\left(\mathrm{H}_{5.1}\right)$, on building habitual aspect in MPB of doctors $\left(\mathrm{H}_{5.2}\right)$ and on consideration of the cost of the drug aspect of MPB of doctors $\left(\mathrm{H}_{5,3}\right)$.

\section{Demographic Factors and Aspects of MPB}

Demographic factors are largely used in describing MPB of doctors ${ }^{20}$. Many previous studies have mentioned that personal and professional traits of doctors such as years of experience, nature of job (public or private) and level of education influence MPB of doctors ${ }^{20,26,33}$.

\subsection{Nature of Service}

A distinction made between public and private doctor is due to some formulary restrictions to be followed by public doctors. For our study, a doctor is considered to be private, if he is working in a hospital which is owned by a person or many people who are managing the whole finances on their own. And a public doctor is the one working in a hospital which is completely and entirely run on the government's funding. Doctors in public hospitals think that their attitude and behaviour are not linked to income level, so they don't tend to change their behaviour of medicine prescription ${ }^{43}$. Private doctors are more likely to prescribe branded drugs in their prescription as compared to the public doctors ${ }^{37}$.

Private doctors prescribe medicine more according to pharmaceutical company's expectations ${ }^{23}$. Therefore, medicine prescription decision is not only taken by a doctor but it is the result of the communication of both doctor as well as MRs of pharmaceutical companies ${ }^{17}$.

Taneja ${ }^{52}$ analysed the influence of promotional tools of pharmaceutical companies on MPB of private and public doctors and concluded that private doctors rated MRs and continuing medical education programmes programs as major factors in influencing their behaviour as compared to public sector doctors. The empirical analysis of the previous studies have also observed the same conclusion i.e., private doctors are majorly influenced by marketing or promotional tools of pharmaceutical companies and they are early prescribers of promoted drugs as compared to the public doctors $\frac{13,20}{}$.

Kotwani et al. $\frac{34}{}$ reported that public doctors in Delhi prescribed more antibiotics in their prescription as compared to private doctors due to the influence of information provided by MRs. Huskamp et al. 29 in their study on "How quickly do physicians adopted new drugs" investigated the relationship between MPB of doctors across their nature of service, and they found that public doctors are early prescribers of new drugs as compared to doctors who are in private practice. Another study on Canadian doctors observed the same conclusion that public doctors prescribe promoted drugs sooner as compared to private doctors of Canada ${ }^{19}$. Bulte and Lilien ${ }^{10}$ concluded that public doctors due to less busy schedules adopt new drugs early as compared to private doctors. On the other hand, two studies have concluded that there is no association between MPB of doctors and the nature of service of doctors $\frac{16,19}{}$.

Thus, on the basis of past studies, it is plausible to hypothesise that:

$\mathrm{H}_{6.1}$ : Early prescription of new drugs aspect of MPB of doctors differs across differently practicing doctors.

$\mathrm{H}_{6.2}$ : Habitual aspect of MPB of doctors differs across differently practicing doctors.

$\mathrm{H}_{6.3}$ : Cost aspect of MPB of doctors differs across differently practicing doctors.

\subsection{Education}

Various researches have reported different conclusions of the influence of marketing strategies of pharmaceutical companies on MPB of doctors across their educational profile. On the basis of educational qualification, doctors were divided in two categories. Doctors with MD or higher degree were considered as 'specialists' whereas with only MBBS degree were taken to be the 'general physicians'. Ten researches have concluded that specialist (MD) doctors are early adopters of new drugs and these specialists are called opinion leaders or influencers. The general physicians who follow the prescription of these specialist doctors or opinion leaders are known as followers.

Pharmaceutical companies target specialist doctors while framing their marketing policies and spend a huge amount in promoting their drug to specialist doctors as compared to general physicians $\frac{12,18}{}$. Garjon et al. $\frac{18}{}$ have taken eight new drugs in an empirical survey to find out the impact of promotion of new drugs on doctors across their educational 
qualification. They concluded that specialized doctors (MD) adopted new drugs in their prescription behaviour much earlier as compared to the general physicians.

On the other hand, Mizik \& Jacobson ${ }^{41}$ quantified the influence of 'detailing' by MRs and 'free drug samples' on prescription behaviour of general physicians and specialist doctors. They have reported that general physicians are much easily influenced by MRs, and ask for free drug samples from MRs. Therefore, general physicians prescribe more promoted drugs in their medicine prescription as compared to prescriptions by specialist doctors. Another study has investigated the influence of 'academic detailing' by MRs on Canadian doctors across their education. They also arrived at the same conclusion that general physicians prescribe the promoted drug earlier than the specialist doctors ${ }^{24}$.

Three studies have concluded that general physicians rated information given by MRs as major influential factors as compared to the specialist doctors who considered information provided in continuing educational programs as a major influential factor in their prescription ${ }^{39,44,46}$.

Thus, in the light of above mentioned studies, we hypothesise that:

$\mathrm{H}_{7.1}$ : Early prescription of new drugs aspect of MPB of doctors differs across doctor's education.

$\mathrm{H}_{7.2}:$ Habitual aspect of MPB of doctors differs across doctor's education.

$\mathrm{H}_{7.3}$ : Cost aspect of MPB of doctors differs across doctor's education.

\subsection{Experience}

Medicine prescription decision is influenced by cognitive heuristics, or we can say that doctor chooses the drug according to his experience $\frac{35}{1}$ i.e., the doctor learns about the drug from experience. Doctors prescribe the drug again only if they have a positive treatment experience from the use of the drug by the patients. Pharmaceutical companies notice learning psychology of the doctors and accordingly, companies frame their marketing campaigns for promoting new drugs.

Kasliwal ${ }^{33}$ in her study concluded that the influence of the promotional tools of pharmaceutical companies varies across different demographic characteristics of doctors. She further added that the influence of promotional tools on MPB is higher on less experienced doctors as compared to the older or more experienced doctors. Pharmaceutical companies target less experienced doctors while promoting their new drugs as compared to the more experienced doctors. Less experienced doctors have higher propensity for innovation, therefore, they are likely to attend continu- ing educational programs sponsored by pharmaceutical companies and also request for free drug samples during the discussions with MRs $1,12,20,21,29$.

On the other hand, many studies mentioned in their work that experienced doctors are opinion leaders and they are influencers ${ }^{26}$. In India approximately 32 percent of the pharmaceutical industry's marketing budget is spent on opinion doctors especially on making personal calls to them. It is estimated that the whole pharmaceutical industry spends approximately 24 percent of the total market budget of their new drug on opinion leaders.

However, few previous studies have reported that experience does not play any influential role in the MPB of doctors 13,37 .

For our study, a doctor having less than 15 years of experience is labelled to be with 'less experience' whereas the one with more than 15 years is considered to be a doctor with 'high experience'.

Hence, we hypothesise that:

$\mathrm{H}_{8.1}$ : Early prescription of new drugs aspect of MPB of

doctors differs across doctor's years of experience.

$\mathrm{H}_{8.2}:$ Habitual aspect of MPB of doctors differs across doctor's years of experience.

$\mathrm{H}_{8.3}$ : Cost aspect of MPB of doctors differs across doctor's years of experience.

\section{Research Methodology}

A questionnaire (link given) was designed to explore factors related to MRs influencing MPB socio-demographic factors by: type of practice setting (private and public), education level (general and specialist doctor) years of experience and dimensions related to MRs. Responses were collected from 150 doctors working in Delhi. The study covered a period of five months (June 2015 - October 2015) which was utilised for collecting the primary data. Respondents were asked to rate all questions on a five-point Likert Scale with 1 indicating 'strongly agree' and 5 indicating 'strongly disagree'.

Various pharmaceutical, marketing journals, magazines, reports and websites were referred for identifying major factors influencing MPB of doctors and for developing hypotheses.

The quota sampling technique ${ }^{\mathrm{d}}$ was used to draw a sample of doctors. The population of doctors located in the city of Delhi was first segmented into mutually exclusive subgroups on the basis of working in public hospitals, working in private hospitals and doing private practice. Then, a 
random sample of general practitioners and specialists was drawn from the database of subgroups of doctors.

Regression Analysis is used to test the hypotheses related to influence of factors affecting MPB of doctors. Our research also examined differential effects across doctor's field of specialisation, his years of experience and employment sector. Analysis of Variance (ANOVA) is used to test the hypotheses related to demographic antecedents affecting MPB of doctors.

\section{Analysis}

\subsection{Reliability Test}

Reliability is one of the important elements in the assessment of a measuring instrument. The popular measure, Cronbach's alpha, is used to check the reliability of the multi item scale. A construct having reliability greater than 0.6 shows that there is internal consistency between the scale. The results of the reliability test ${ }^{\mathrm{b}}$ reported in Table 1 indicate that Cronbach's alpha of all the variables is more than 0.6 except for kind of information and professionalism factor which implies that there is high degree of inter-correlation among the variables. From Table 1, we can say that communication skill has the highest consistency.

Table 1. Reliability Results for Scales used in the Study

\begin{tabular}{|c|c|c|c|}
\hline Variables & $\begin{array}{c}\text { Grand } \\
\text { Mean }\end{array}$ & $\begin{array}{c}\text { Standard } \\
\text { Deviation } \\
\text { (SD) }\end{array}$ & $\begin{array}{c}\text { Cronbach's } \\
\text { Alpha }\end{array}$ \\
\hline Level of Knowledge & 40.5122 & 4.74406 & 0.689 \\
\hline Kind of Information & 20.0976 & 2.76410 & 0.574 \\
\hline Communication Skills & & 3.23246 & 0.783 \\
\hline Frequency of Visits & 17.3590 & 3.35988 & 0.694 \\
\hline Professionalism Factor & 11.6750 & 1.92670 & 0.547 \\
\hline $\begin{array}{c}\text { Net Effect on } \\
\text { Prescription behaviour }\end{array}$ & 9.8780 & 2.55142 & 0.681 \\
\hline
\end{tabular}

\subsection{Regression Analysis of Aspects of MPB of Doctors}

This section investigates the influence of above mentioned antecedents on different aspects of MPB of doctors using multiple regression analysis technique, separately for each aspect of the MPB of doctors.

\subsubsection{Early Prescription of New Drugs}

This section investigates the influence of above mentioned antecedents on the early prescription of new drug aspect of MPB of doctors.

Regarding the significance of each variable in context of early prescription of new drugs aspect of MPB of doctors (Table 2), the four antecedents i.e., level of knowledge, kind of information, communication skills and professionalism factor of MRs are the significant predictors of early prescription of new drugs aspect of MPB of doctors at significance level of 5 percent or lesser.

Therefore, the above empirical analysis lends support to four hypotheses $\mathrm{H}_{1.1,}, \mathrm{H}_{2.1,}, \mathrm{H}_{3.1}$ and $\mathrm{H}_{5.1}$.

Table 2. Regression Analysis of Early Prescription of New Drugs Aspect of MPB of Doctors

\section{Dependent Variable - Early Prescription of New Drugs Aspect of MPB \\ Independent Variables - Factors of MRs}

\begin{tabular}{|c|c|c|c|}
\hline Factors of MRs & $\begin{array}{c}\text { Beta } \\
\text { Value }\end{array}$ & $\begin{array}{c}\text { F-Statistic } \\
\text { (p value) }\end{array}$ & $\mathbf{R}^{2}$ \\
\hline Level of Knowledge & 0.103 & $\begin{array}{c}9.188 \\
(.004)\end{array}$ & .1756 \\
\hline Kind of Information & 0.222 & $\begin{array}{l}5.157 \\
\mathbf{( . 0 2 9 )}\end{array}$ & .0237 \\
\hline Communication Skills & 0.145 & $\begin{array}{l}8.566 \\
(.000)\end{array}$ & .2970 \\
\hline Frequent of Visits & 0.189 & $\begin{array}{l}1.724 \\
\mathbf{( . 1 9 7 )}\end{array}$ & .0480 \\
\hline Professionalism & 0.142 & $\begin{array}{l}2.247 \\
\mathbf{( . 0 0 1 )}\end{array}$ & .1892 \\
\hline
\end{tabular}

Note: Significance level $\mathrm{p} \leq 0.05$.

\subsubsection{Habitual Aspect}

This section examines the influence of antecedents on the habitual aspect of MPB of doctors (Table 3).

On the basis of previous studies, regression statistical tool was used to investigate the influence of antecedent variables on the habitual aspect of MPB of doctors.

The four factors i.e., level of knowledge of MRs, kind of information given by MRs, communication skills of MRs and professionalism factor of MRs are the significant predictors of habitual aspect of MPB of doctors at significance level of 5 percent. 
Therefore, the above empirical analysis lends support to four hypotheses $\mathrm{H}_{1.2,} \mathrm{H}_{2.2,} \mathrm{H}_{3.2,}$ and $\mathrm{H}_{5.2}$.

Table 3. Regression Analysis of Habitual Aspect of MPB of doctors

\section{Dependent Variable -Habitual aspect of MPB}

Independent Variables - Factors of MRs

\begin{tabular}{|c|c|c|c|}
\hline Factors of MRs & $\begin{array}{c}\text { Beta } \\
\text { Value }\end{array}$ & $\begin{array}{c}\text { F-Statistic } \\
\text { (p value) }\end{array}$ & $\mathbf{R}^{2}$ \\
\hline Level of Knowledge & .321 & $\begin{array}{l}.1706 \\
(.043)\end{array}$ & .0438 \\
\hline Kind of Information & .281 & $\begin{array}{l}.0412 \\
(.042)\end{array}$ & .0441 \\
\hline Communication Skills & .167 & $\begin{array}{l}.1197 \\
\mathbf{( . 0 1 6}\end{array}$ & .0639 \\
\hline Frequency of Visits & .187 & $\begin{array}{l}.0259 \\
(.098)\end{array}$ & .02871 \\
\hline Professionalism & .177 & $\begin{array}{l}.2007 \\
(.003)\end{array}$ & .1031 \\
\hline
\end{tabular}

Note: Significance level $\mathrm{p} \leq 0.05$.

\subsubsection{Cost of the Drug}

This section investigates the influence of above mentioned antecedents on the cost of the drug aspect of MPB of doctors (Table 4).

Table 4. Regression Analysis of Cost of the Drug Aspect of MPB of Doctors

Dependent Variable - Cost of the Drug aspect of MPB Independent Variable - Factors of MRs

\begin{tabular}{|c|c|c|c|}
\hline Factors of MRs & $\begin{array}{c}\text { Beta } \\
\text { Value }\end{array}$ & $\begin{array}{c}\text { F-Statistic } \\
\text { (p value) }\end{array}$ & $\mathbf{R}^{2}$ \\
\hline Level of Knowledge & .320 & $\begin{array}{l}0.941 \\
(\mathbf{. 0 4 6})\end{array}$ & .0250 \\
\hline Kind of Information & .146 & $\begin{array}{c}7.909 \\
\mathbf{( . 0 0 0 )}\end{array}$ & .1498 \\
\hline Communication & .153 & $\begin{array}{l}2.926 \\
(.431)\end{array}$ & .0114 \\
\hline Skills & & $\begin{array}{l}2.254 \\
(.099)\end{array}$ & .0562 \\
\hline Frequency of Visits & .177 & $\begin{array}{l}1.395 \\
(.260)\end{array}$ & .0686 \\
\hline Professionalism & .190 & & \\
\hline
\end{tabular}

Note: Significance level $\mathrm{p} \leq 0.05$.

The two factors i.e., level of knowledge of MRs, kind of information given by MRs, are the significant predictors of the cost aspect of MPB of doctors at significance level of 5 percent.

Therefore, the above empirical analysis lends support to two hypotheses $\mathrm{H}_{1.3}$ and $\mathrm{H}_{2.3}$.

\subsection{Analysis of Demographic Differences in the MPB of Doctors: Using Analysis of Variance $\left(\mathrm{ANOVA}^{\mathrm{c}}\right)$}

One-way ANOVA analysis was used to assess the impact of demographic factors on MPB of doctors. This section describes the results of ANOVA analysis by taking the aspects of MPB of doctors as scalar variables and demographic factors as categorical variables.

The ANOVA analysis of demographic based differences in the aspects of MPB of doctors is explained further in the ensuing sections.

\subsubsection{ANOVA Analysis of Aspects of MPB of Doctors}

This section investigates the ANOVA analysis of education and employment-based differences in the aspects of MPB of doctors.

On the basis of Table 5 we can say that, early prescription of new drugs aspect of MPB of doctors differs across education level and employment sector because in both cases the significance level is less than .05 . Thus, the findings lend support to the acceptance of the two hypotheses i.e. $\mathrm{H}_{6.1}$ and $\mathrm{H}_{7.1 \text {. }}$

\subsubsection{ANOVA Analysis of Experience Differences in the MPB of Doctors}

This section investigates the ANOVA analysis of experience based differences in the aspects of MPB of doctors.

On the basis of Table 6 we can say that, prescription behaviour of doctors that is Aspect 1 (E1-Early prescription of new drugs aspect of MPB), Aspect 2 (E2-Habitual aspect of MPB) and Aspect 3 (E3-Cost aspect of MPB) do not differ across experience (years of practice) because in none of the cases the significance level is less than .05 . Thus, $\mathrm{H}_{8.1}, \mathrm{H}_{8.2}$ and $\mathrm{H}_{8.3}$ are rejected. 
Table 5. ANOVA Analysis of Education and Employment-based Differences in the MPB of Doctors

Dependent Variable - Effect 1 (Early prescription of New Drugs Aspect of MPB)

- Effect 2 (Habitual Aspect of MPB)

- Effect 3 (Cost Aspect of MPB)

Independent Variable - Education

- Employment Sector

\begin{tabular}{|c|c|c|c|c|c|}
\hline & $\begin{array}{c}\text { Aspects of } \\
\text { MPB }\end{array}$ & General & Specialist & Public Doctor & Private Doctor \\
\hline \multirow{3}{*}{ Mean } & E1 & 3.1765 & 4.0417 & 3.9231 & 3.2667 \\
\hline & E2 & 3.0588 & 3.5 & 3.3077 & 3.3333 \\
\hline & E3 & 2.5882 & 3.0833 & 2.7692 & 3.0667 \\
\hline \multirow{3}{*}{ S.D } & E1 & 0.88284 & 0.85867 & 0.89098 & 0.96115 \\
\hline & E2 & 0.89935 & 1.14208 & 1.2318 & 0.9759 \\
\hline & E3 & 0.93934 & 1.38051 & 1.1767 & 1.33452 \\
\hline \multirow{3}{*}{ F-Statistic ( $\mathrm{p}$ value) } & E1 & \multicolumn{2}{|c|}{$9.872(\mathbf{0 . 0 0 3})$} & \multicolumn{2}{|c|}{$4.876(\mathbf{0 . 0 3 3 )}$} \\
\hline & $\mathrm{E} 2$ & \multicolumn{2}{|c|}{$1.759(0.192)$} & \multicolumn{2}{|c|}{$0.005(0.942)$} \\
\hline & E3 & \multicolumn{2}{|c|}{$1.642(0.208)$} & \multicolumn{2}{|c|}{$0.551(0.462)$} \\
\hline
\end{tabular}

Note: Significance level $\mathrm{p} \leq 0.05$.

Table 6. ANOVA analysis of Experience based Differences in the MPB of Doctors

Dependent Variable - Effect 1 (Early Prescription of New Drugs Aspect of MPB).

- Effect 2 (Habitual Aspect of MPB).

- Effect 3 (Cost Aspect of MPB).

Independent Variable - Experience

\begin{tabular}{|c|c|c|c|c|c|c|}
\hline Experience & $\begin{array}{c}\text { Aspects of } \\
\text { MPB }\end{array}$ & 0 to 5 & 6 to 10 & 11 to 15 & 16 to 20 & 21 and above \\
\hline \multirow{3}{*}{ Mean } & E1 & 3.83333 & 3 & 3.8889 & 4.3333 & 3.6667 \\
\hline & E2 & 3.6667 & 3 & 3.5556 & 3.6667 & 2.7778 \\
\hline & E3 & 3.25 & 3 & 2.5556 & 3 & 2.5556 \\
\hline \multirow{3}{*}{ S.D } & E1 & 0.83485 & 1.19523 & 0.92796 & 0.57735 & 0.86603 \\
\hline & E2 & 0.98473 & 1.19523 & 0.72648 & 1.52753 & 1.09291 \\
\hline & E3 & 1.28806 & 1.41421 & 1.13039 & 1.73205 & 1.01379 \\
\hline \multirow{3}{*}{ F Statistic ( $\mathrm{p}$ value) } & E1 & \multicolumn{5}{|c|}{$1.63(0.188)$} \\
\hline & E2 & \multicolumn{5}{|c|}{$1.327(0.279)$} \\
\hline & E3 & \multicolumn{5}{|c|}{$0.587(0.674)$} \\
\hline
\end{tabular}

Note: Significance level $\mathrm{p} \leq 0.05$. 


\section{Conclusion and Policy Implications}

The study provides an idea about how pharmaceutical marketing works, role of MR and expectations of doctors from MRs for prescribing their company's products and the reason behind early prescription of new drugs. The results of the empirical analysis concluded that the knowledge, kind of information, communication skills and professionalism factor of MRs influence doctor towards early prescription of new drugs. Many past researches have also validated the conclusion of this study that knowledge and objective information given by MRs are important drivers in the MPB of doctors especially in the case of early prescription of new drugs.

The results further concluded that the knowledge, kind of information, communication skills and professionalism of MRs influence doctors' habitual behaviour towards prescription of drugs. Past empirical researches also analysed the MPB of doctors, and they have concluded that doctors do spare time to interact with MRs of pharmaceutical companies for updating their knowledge about availability of drugs in the market. Doctors consider MRs as vital source of information about drugs and the image of the pharmaceutical companies improves in the mind of the doctors when MRs provide accurate and scientific information about the drugs of their pharmaceutical companies.

The results also concluded that knowledge of MRs and the kind of information given by MRs are significant predictors of cost aspect of MPB of doctors. Sometimes doctors choose low cost drugs while prescribing medicines to their patients because they think that low cost drugs improve the adherence by the patient towards treatment. The present study further indicated that early prescription of new drugs aspect of MPB of doctors differs across their levels of education and employment sector.

Pharmaceutical companies should provide proper training to MRs to update their knowledge about the drugs and to improve their communication skills. Pharmaceutical companies should give preference to frequent visits of MRs to meet doctors for promoting new drugs. Pharmaceutical companies should design the information content about the new drugs in such a way that it should increase the scientific knowledge of doctors about new drugs which in turn enhances the doctors' competency and performance in the treatment of patients.
Therefore, the results conclude that:

- MR plays the most important role in promoting the drugs of the respective pharmaceutical companies.

- The most effective medium for brand recall is frequent reminders through MR.

- The doctors' expectations from MRs is their in-depth product knowledge, communication skills and professionalism while promoting their product and representing their company to the doctors.

- The reason for shifting the brand from one company to another is less frequent visits of MR.

- Interactions with MRs result in early prescription of new drugs differ across educational profile and nature of practice of doctors but not years of experience.

This study is useful for pharmaceutical companies in developing doctor's loyalty to particular brands. It gives guidelines to pharmaceutical companies for promoting a new drug in the presence of competing older drugs. The role of MRs in pharmaceutical industry is significant in improving the efficiency and effectiveness in medical services.

Finally, this study provides a different perspective for future research on prescription behaviour by including other factors which would possibly provide different orientation to prescription loyalty studies.

\section{References}

1. Abdelaziz AB, Harrabi I, Rahmani S. Attitudes of general practitioners to pharmaceutical sales representatives in Sousse. East Mediterranean Health J. 2003; 9(5-6):1075-8.

2. Accenture. Physicians seek more detailed, comparative and customized information from pharmaceutical representatives. Retrieved September 16 2003. accen-ture.com/xd/ $\mathrm{xd}$.asp?it=enweb\&xd=_dyndynamicpressrelease_630.xml

3. Alkhateeb FM, Khanfar NM, Clauson KA. Characteristics of physicians who frequently see pharmaceutical sales representatives. J Hosp Mark Public Relations. 2009; 19(1):2-14. PMid: 19197653. https://doi. org/10.1080/15390940802581374

4. Allan GM, Innes G. Do family doctors know the costs of medical care. Can Fam Phys. 2004; 50:263-70.

5. Allan GM, Innes G. Family practice residents' awareness of medical care costs in British Columbia. Fam Med. 2002; 34:106-1. 
6. Arora, Usha, Taneja, Girish. An analytical study of doctors behaviour towards marketing of pharmaceutical products. Indian Journal of Marketing. 2006;36 (11):10-13.

7. Bednarik J. Does brand differentiate pharmaceuticals?Neuro Endocrinol Lett. 2005; 26(6):635-2.

8. Berndt ER, Bui LT, Reiley DH, Urban GL. The roles of marketing, product quality and price competition in the growth and composition of the US antiulcer industry. The Economics of New Goods. Chicago: University of Chicago Press; 1997.

9. Bourke J, Roper S. In with the new: the determinants of prescribing innovation by general practitioners in Ireland. Eur J Health Econ. 2012; 13:393-07. doi: 10.1007/s10198011-0311-5. PMid: 21503785. https://doi.org/10.1007/ s10198-011-0311-5

10. Bulte C, Lilien G. Medical innovation revisited: social contagion versus marketing effort. Am J Sociol. 2001; 106:1409-35.doi: 10.1086/320819 https://doi. org/10.1086/320819

11. Caudill T, Johnson M, Rich E, McKinney W. Doctors, pharmaceutical representatives and the cost of prescribing. Arch Fam Med. 1996; 5(4):201-6. PMid: 8769907. https://doi. org/10.1001/archfami.5.4.201

12. Coleman JS, Elihu K, Herbert M. Medical Innovation: A Diffusion Study. Indianapolis: The Bobbs-Merrill Company; 1966.

13. Corrigan M, Glass H. Physician participation in clinical studies and subsequent prescribing of new drugs. P\&T.2005; 30:60-6.

14. Cosceilli A, Shum M. An empirical model of learning andpatient spillovers in new drug entry. J. Econom. 2004; 122:213-46. https://doi.org/10.1016/j.jeconom.2003.09.002

15. Doney PM, Cannon JP. An examination of the nature of trust in buyer-seller relationships. J. Mark. 1997; 61:35-51. https://doi.org/10.2307/1251829 https://doi. org/10.1177/002224299706100203

16. Dybdahl T, Søndergaard J, Kragstrup J, Kristiansen I, Andersen M. Primary care physicians' adoption of new drugs is not associated with their clinical interests:a pharmacoepidemiologic study. Scand J Prim Health Care. 2011; 29:117-21. PMid: 21510719 PMCid: PMC3347948. doi: 10.3109/02813432.2011.570024 https://doi.org/10.3109/02 813432.2011.570024

17. Edwards I, Jones M, Higgs JG. What is collaborative reasoning? Advances in Physiotherapy. 2004; 6:70-83. https:// doi.org/10.1080/14038190410018938

18. Garjon F, Azparren A, Vergara I, Azaola B, Loayssa J.Adoption of new drugs by physicians: a survival analysis. BMC Health Serv Res. 2012; 12:56. PMid: 22401169PMCid: PMC3353238 doi: 10.1186/1472-6963-12-56https://doi. org/10.1186/1472-6963-12-56

19. Glass H, Dalton D. Profiles of phase IV investigators and subsequent prescribing of the study drug. J Pharm Mark
Manage. 2006; 17:3-17. doi: 10.3109/J058v17n03_02 https://doi.org/10.3109/J058v17n03_02

20. Glass HE, Rosenthal B. Demographics, practices, and prescribing characteristics of doctors who are early adopters of new drugs. Pharmacy and Therapeutics. 2004; 29(1):699708.

21. Glass H, Rosenthal B. Post-launch clinical investigator drug prescribing in the US. Int J Pharm Med. 2005; 19:97-104. doi: 10.2165/00124363-200519020-00005 https://doi. org/10.2165/00124363-200519020-00005

22. Gonul FF, Carter F, Petrova E, Srinivasan K. Promotion of prescription drugs and its impact on doctors' choice behavior. J. Mark. 2001; 65:79-90. https://doi.org/10.1509/ jmkg.65.3.79.18329

23. Grone O, Garcia-Barbero M. Trends in integrated care - reflections on conceptual issues. World Health Organization: Copenhagen; EUR/02/5037864. 2002.

24. Groves K, Schellinck T, Sketris I, MacKinnon N. Identifying early prescribers of cycloxygenase-2 inhibitors (COX-2 s) in Nova Scotia, Canada: considerations for targeted academic detailing. Res Social Adm Pharm. 2010; 6:257-67. PMid: 20813338. doi: 10.1016/j.sapharm.2 https://doi. org/10.1016/j.sapharm.2009.09.003

25. Hart J, Salman H, Bergman M, Neuman V, Rudniki C, et al. Do drug costs affect physicians' prescription decisions?J Intern Med. 1997; 241:415-20. https://doi.org/10.1046/ j.1365-2796.1997.137143000.x

26. Hartzema AG, Christensen DB. Nonmedical factors associated with the prescribing volume among family practitioners in an HMO. Medical Care. 1983; 21:990-1000. https://doi.org/10.1097/00005650-198310000-0000537.

27. Health Strategies Group, Inc. Pharma SFE. 2003. www. healthstrategies.com/products/sfe_reports.html

28. Henry J. National Survey of Doctors: Doctors and Prescription Drugs. Kaiser Family Foundation. 2002.

29. Huskamp H, O’Malley A, Horvitz-Lennon M, Taub A, Berndt ER, Donohue J. How quickly do physicians adopt new drugs? The case of second-generation anti-psychotics. Psychiatr Serv. 2013; 64:324-0. PMid: 23280376 PMCid: PMC3907700. doi: 10.1176/appi.ps.201200186 https:/doi. org/10.1176/appi.ps.201200186

30. IMS Health. IMS forecasts global pharmaceutical market growth of 4-6\% in 2010; predicts 4-7\% expansion through 2013. Retrieved March 16, 2010. www.imshealth.com: http://www.imshealth.com

31. Janakiraman R, Dutta S, Sismeiro C, Stern P. Doctors 'persistence and its implications for their response to promotion of prescription drugs. Management Science. 2008;54(6):10803. https://doi.org/10.1287/mnsc.1070.0799

32. John AH. Effects of an educational intervention on residents' knowledge and attitudes toward interactions with pharmaceutical representatives. Gen Internal Med. 1997; 
12(10):639-2. PMid: 9346461 PMCid: PMC1497177. https://doi.org/10.1046/j.1525-1497.1997.07126.x

33. Kasliwal N. "A study of psychosocial factors on doctors prescribing behavior - An Empirical Study in India.Journal of Business and Management. 2013; 13(2):5-0.e-ISSN: 2278-487X, p-ISSN: 2319-7668. https:// doi. org/10.9790/487X-1320510

34. Kotwani A, Wattal C, Katewa S, Joshi P, Holloway K. Factors influencing primary care physicians to prescribe antibiotics in Delhi India. Family Practice. 2010; 27:684-0. PMid: 20660529. https://doi.org/10.1093/fampra/cmq059

35. Laroche M, Bergeron J, Goutaland C. How intangibility affects perceived risk: the moderating role of knowledge and involvement. Journal of Services Marketing. 2003; 17(2):122-0. https://doi.org/10.1108/08876040310467907

36. Layton RM, Sritanyarat W, Chadbunchachai S. Sources of information for new drugs among doctors in Thailand . Pharm World Science. 2007; 29(6):619-7. PMid: 17710562. https://doi.org/10.1007/s11096-007-9112-4

37. Lin S, Jan K, Kao J. Colleague interactions and new drug prescribing behavior: the case of the initial prescription of antidepressants in Taiwanese medical centers. Soc Sci Med. 2011; 73:1208-3. PMid: 21962150. doi: 10.1016/j. socscimed.2011.06.065. https://doi.org/10.1016/j.socscimed.2011.06.065

38. Lurie N, Rich E, Simpson D. Pharmaceutical representatives in academic medical centers. J Gen Intern Med.1990; 5:2404. PMid: 2341925. https://doi.org/10.1007/ BF02600542

39. McGettigan P, Golden J, Fryer J, Chan R, Feely J. Prescribers prefer people: the sources of information used by doctors for prescribing suggest that the medium is more important than the message. Brit J Clin Pharmacol. 2001; 51(2):1849. PMid: 11259994 PMCid: PMC2014444. https://doi. org/10.1111/j.1365-2125.2001.01332.x

40. Mckinney WP. Attitudes of internal medicine faculty and residents toward professional interaction with pharmaceutical sales representatives. JAMA 1693. 1990;264(13):1693-. PMid: 2398609. https://doi. org/10.1001/ jama.1990.03450130065028

41. Mizik N, Jacobson R. Are doctors' easy marks? Quantifying the effects of detailing and sampling on new prescriptions. Management Science. 2004; 50(12):1704-5. https://doi. org/10.1287/mnsc.1040.0281

42. Narayanan S, Manchanda P, Pradeep. Temporal differences in the role of marketing communication in new products categories. J Mark Res. 2005 Aug; 42:278-0. https://doi. org/10.1509/jmkr.2005.42.3.278

43. Norris P, Herxheimerl A, Lexchin J, Mansfield P. Drug Promotion: What we know, what we have yet to learn. World Health Organization; 2004. p. 11.
44. Peay M, Peay E. Innovation in high risk drug therapy. Soc Sci Med. 1994; 39:39-2. doi: 10.1016/0277-9536(94)90164-3 https://doi.org/10.1016/0277-9536(94)90164-3

45. Prosser H, Walley T. A qualitative study of GP's and PCO stakeholders' views on the importance and influence of cost on prescribing. Soc Sci Med. 2005; 60:1335-6. PMid: 15626528. https://doi.org/10.1016/j.socscimed.2004.07.013

46. Prosser H, Almond S, Walley T. Influences on GPs' decision to prescribe new drugs - the importance of who says what Family Practice. 2003; 20:61-. PMid: 12509373.https://doi. org/10.1093/fampra/20.1.61

47. Prounis C. Successful sales management. What doctors want? Pharmaceutical Executive Suppl. 2003. p. 12-9

48. Rajan TD. Getting into the doctor's mind. Express Pulse.2006; 4.

49. Sahad PV, Sharma EK. The long term prescription. Business Today; 2005 Dec. p. 138.

50. Scott J. Docs want to hear from knowledgeable reps. 2003 Aug. pharm-rep.adv100.com/pharmrep/article/ articleDetail.jsp?id=118400

51. Higgins SP. Drug representatives: giving you lunch or stealing your soul? Dermatology Online J. 2007; 13(4):5.

52. Taneja G. Impact of pharmaceutical industry promotion mix on doctors prescribing behaviour. Asia-Pacific Business Review. 2008; 4:13-. https://doi. org/10.1177/097324700800400408

53. Theodorou M, Tsiantou VV, Pavlakis A. Factors influencing prescribing behaviour of doctors in Greece andCyprus: results from a questionnaire based survey". BMC Health Serv Res. 2009; 9:2-. PMid: 19695079 PMCid: PMC2737540. https://doi.org/10.1186/1472-6963-9-150

54. Wazana A. Doctors and the pharmaceutical industry: is a gift ever just a gift? JAMA. 2000; 283(3):373-0. https://doi. org/10.1001/jama.283.3.373

55. Wright RF, Lundstrom WJ. Doctors' perceptions of pharmaceutical sales representatives: a model for analyzing the customer relationship. Journal of Medical Marketing: Device, Diagnostic and Pharmaceutical Marketing. 2004; 4(1):29-8. https://doi.org/10.1057/palgrave.jmm.5040140

56. Ziegler MG, Lew P, Singer CB. The accuracy of drug information from pharmaceutical sales representatives. JAMA. 1995; 273:1296-. https://doi.org/10.1001/ jama.1995.03520400066047

\section{Notes}

${ }^{a} \mathrm{MRs}$ of pharmaceutical companies provide daily use things like prescription pads, stamps, paperweights etc to doctors to keep their brand in their memory at the time of medicine prescription. These "Brand reminders" may vary from desktop items to minor medical equipment. Doctors receive 
information on new drugs primarily through visits by MRs who use flip charts, introduced by Glexo in 1972, as their main presentation aid for this purpose. These flip charts show the benefits of their drugs over the drugs of other companies.

${ }^{b}$ The reliability test reflects the internal consistency of the indicators measuring a given construct. Therefore, before the hypotheses are tested the reliability of the measurement scales should be checked. In general, the reliability of the construct should be greater than 0.6 in order to meet with the general requirement of reliability for research instruments.

'The Analysis of Variance (ANOVA) is a statistical technique used to compare means for a scale level dependent variable across a categorical nominal variable (Gil et al. 2006).
dQuota Sampling is one of the non-probability sampling techniques in which the interviewer or the researcher selects the sample based on the judgement or quota specified on the sub-groups of the given population.

\section{Link to the Questionnaire}

https://docs.google.com/forms/d/e/1FAIpQLSefW8pllAvlFIVjGvkfONjFX waz3qqTgmBWXYqP8qEejWHqWA/viewform 